\title{
Properties of N-butyl-N-methyl-pyrrolidinium Bis(trifluoromethanesulfonyl) Imide Based Electrolytes as a Function of Lithium Bis(trifluoromethanesulfonyl) Imide Doping
}

\author{
Jae-Kwang Kim*, Du-Hyun Lim ${ }^{\dagger}$, Johan Scheers, Jagath Pitawala, Susanne Wilken, Patrik Johansson, \\ Jou-Hyeon Ahn", Aleksandar Matic and Per Jacobsson \\ Department of Applied Physics, Chalmers University of Technology, 41296 Göteborg, Sweden \\ 'Department of Chemical \& Biological Engineering, Gyeongsang National University, 900, Gajwa-dong, Jinju 660-
}

\author{
701, Korea
}

(Received March 14, 2011 : Accepted May 30, 2011)

\begin{abstract}
In this study we have investigated the Li-ion coordination, thermal behavior and electrochemical stability of N-butyl-N-methyl-pyrrolidinium bis(trifluoromethanesulfonyl)imide (Py $\mathrm{y}_{14} \mathrm{TFSI}$ ) with lithium bis(trifluoromethanesulfony)imide (LiTFSI) doping intended for use as electrolytes for lithium batteries. The ionic conductivity is reduced and glass transition temperature $\left(\mathrm{T}_{\mathrm{g}}\right)$ increases with LiTFSI doping concentration. Also, the electrochemical stability increases with LiTFSI doping. A high LiTFSI doping could enhance the electrochemical stability of electrolytes for lithium batteries, whereas the decrease in the ionic conductivity limits the capacity of the battery.
\end{abstract}

Keywords : Ionic liquid electrolyte, LiTFSI doping, Li-ion coordination, Electrochemical stability

\section{Introduction}

Ionic liquids (ILs) offer a chance to enhance safety and environmental friendliness of electrochemical power sources such as solar cells, supercapacitors, fuel cells, and lithium batteries. In addition, owning to a high thermal stability they can be used in device operating at high temperatures, not possible with current technology based on commercial organic electrolytes of these electrochemical power sources. Other key advantages of ILs are high energy density and applicability to high voltage batteries for transportation applications, such as in electric vehicles (EVs) and hybrid-electric vehicles (HEVs), since they can provide a wide electrochemical window up to $5 \mathrm{~V}$, and non flammability resulting in outstanding safety advantages. ${ }^{1-3)}$

Typical ILs consist of organic cations with delocalized charges, such as imidazolium, pyridinium, pyrrolidinium, ammonium, sulfonium, or phosphonium derivatives, and

*E-mail: jaekwang@chalmers.se fluoroanions, such as $\left[\mathrm{BF}_{4}\right],\left[\mathrm{PF}_{6}\right],\left[\mathrm{CF}_{3} \mathrm{SO}_{3}\right]$, $\left[\left(\mathrm{CF}_{3} \mathrm{SO}_{2}\right)_{2} \mathrm{~N}\right]$, and $\left[\left(\mathrm{FSO}_{2}\right)_{2} \mathrm{~N}\right] \cdot{ }^{4-14)}$ Since numerous combinations of the cationic and anionic structures are possible, physicochemical properties of ILs can be tuned by changing the structure of the component ions. Thus many studies have focused on the design of new ILs by changing the cation- anion combinations.

To obtain an electrolyte the IL has to be doped with a lithium salt, such as $\mathrm{LiPF}_{6}, \mathrm{LiBF}_{4}$, LiTFSI, or LiFSI. The doping level is limited to a domain where the mixture remains liquid at room temperature. In addition, a compromise between the increase in the lithium charge carrier concentration and the concomitant increase in the viscosity and resistivity with increasing lithium salt concentration has to be found for practical applications. ${ }^{15}$ ) To further develop these materials and optimize them for battery applications it is important to understand the influence of Li-salt doping since it is associated with the conductivity and lithium transport number of the electrolyte properties that are known to strongly affect the capacity of lithium batteries. 
In this study, we investigate the influence of lithium salt doping on properties of IL based electrolyte, such as the Li-ion coordination, phase behavior, conductivity, and electrochemical stability. Li-ions strongly coordinated to anions will influence the transport number and therefore the performance of the battery ${ }^{10,16,17)} \mathrm{N}$ butyl-N-methyl-pyrrolidinium bis(trifluoromethanesulfonyl) imide ( $\left.\mathrm{Py}_{14} \mathrm{TFSI}\right)$ and lithium bis(trifluoromethanesulfony) imide (LiTFSI) have been selected for this study. $\mathrm{Py}_{14}$ TFSI has attracted interest for application in lithium batteries because it shows a much wider cathodic decomposition potential compared to non-cyclic and unsaturated cyclic quaternary ammonium ILs, a subambient melting temperature, high ionic conductivity, and ability to form a solid electrolyte interface (SEI) preventing undesired reactions between the carbon anode and the electrolyte. ${ }^{18,19)}$ ILs with the TFSI anion usually show relatively low viscosity and high conductivity, due to the highly delocalized charge which reduces the interactions with neighboring cations. ${ }^{20)}$

\section{Experimental}

$\mathrm{Py}_{14}$ TFSI and LiTFSI were obtained from Aldrich (99\% purity), stored under argon atmosphere and used as received. Electrolytes were prepared for five different

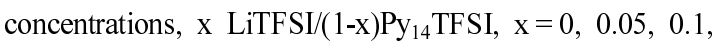
$0.15,0.2$. Raman spectra were recorded on a Bruker IFS 66 Fourier Transform spectrometer, equipped with a FRA 106 Raman module using the $1064 \mathrm{~nm}$ line of a $\mathrm{Nd}$ : YAG laser as excitation source. The laser power was set to $250 \mathrm{~mW}$ and the resolution was $4 \mathrm{~cm}^{-1}$. Differential scanning calorimetry (DSC) experiments were performed to follow the phase behavior of the electrolytes using a Q1000, TA Instruments at a heating rate of $10^{\circ} \mathrm{C} \mathrm{min}^{-1}$. The samples were hermetically sealed in aluminum DSC pan inside a glove box $\left(\mathrm{H}_{2} \mathrm{O}<\right.$ $10 \mathrm{ppm}$ ) under argon atmosphere. Typically the samples were cooled at $20^{\circ} \mathrm{C} \mathrm{min}^{-1}$ from $40^{\circ} \mathrm{C}$ to $-120^{\circ} \mathrm{C}$ and then heated at $10^{\circ} \mathrm{C} \min ^{-1}$ up to $120^{\circ} \mathrm{C}$. The ionic conductivities of the electrolytes were measured from $-20^{\circ} \mathrm{C}$ to $80^{\circ} \mathrm{C}$ in a gold-plated cell with a $1 \mathrm{~mm}$ Teflon spacer, over the frequency range $10^{-1}-10^{6} \mathrm{~Hz}$ using a Novocontrol broadband dielectric spectrometer. The electrochemical stability was determined by linear sweep voltammetry (LSV) of Li/SS cells at a scan rate of $1 \mathrm{mV} \mathrm{s}^{-1}$ at $25^{\circ} \mathrm{C}$.

\section{Results and Discussion}

Raman spectra of the $\mathrm{Py}_{14}$ TFSI based electrolytes containing LiTFSI salt were measured over the frequency range $0-3500 \mathrm{~cm}^{-1}$. Raman spectroscopy is suitable to probe the lithium ion coordination, especially in the range $720-760 \mathrm{~cm}^{-1}$, since the strong mode, corresponding to the contraction-expansion of the whole ion, at $\sim 740 \mathrm{~cm}^{-1}$, is sensitive to interactions. ${ }^{20)}$ In addition the mode is also sensitive to the conformational state of the anion, where the two conformers $C 1$ (cisoid) and $C 2$ (transoid) have spectral components at $\sim 739 \mathrm{~cm}^{-1}$ and $\sim 741 \mathrm{~cm}^{-1}$ respectively. ${ }^{16,17)}$ With the addition of a Li-salt an additional component is usually found at even higher frequencies. ${ }^{21)}$ In Fig. 1 the spectral range around $740 \mathrm{~cm}^{-1}$ band is shown for the pure IL (a) and the three electrolyte concentrations (b-d).

The solid lines of Fig. 1 are results of a bandfit of the experimental spectra (circles), using Lorentzian profiles. Three components are used to describe the band, the two components related to free $C 1$ and $C 2$ conformers and a third component $\left(\sim 748 \mathrm{~cm}^{-1}\right)$ corresponding to Li-ions coordinated TFSI to ions. ${ }^{1720)}$ With increasing LiTFSI concentration the relative intensity of the third component increases. This means that the number of $\mathrm{TFSI}^{-}$interacting with $\mathrm{Li}^{+}$is increasing with lithium doping. From the relative areas of the different components, the average coordination number of $\mathrm{Li}$ with respect to TFSI can be determined through the relation

$$
W=\frac{C_{\text {coord }}}{x}
$$

where $\mathrm{C}_{\text {coord }}$ is the relative area of the third component in the spectrum and $\mathrm{x}$ is the salt concentration.

In the concentration range between $\mathrm{x}=0.1$ and $\mathrm{x}=0.2$ the coordination number $(\mathrm{N})$ is found to be around 2, in agreement with previous studies on LiTFSI doped imidazolium based ionic liquids. ${ }^{21)}$ Furthermore, the concentration of $C l$ conformers decreases while the concentration of $C 2$ conformer increases slightly. A coordination number of 2 could point to the existence of $\left[\mathrm{Li}(\mathrm{TFSI})_{2}\right]^{-}$triplets, as suggested previously. ${ }^{16}$ Such coordination should be very stable and can be related to the very low $\mathrm{Li}^{+}$transference number observed at these LiTFSI concentration. ${ }^{22)}$

The ionic conductivity of an electrolyte depends on the number, charge, and mobility of the carrier ions. 

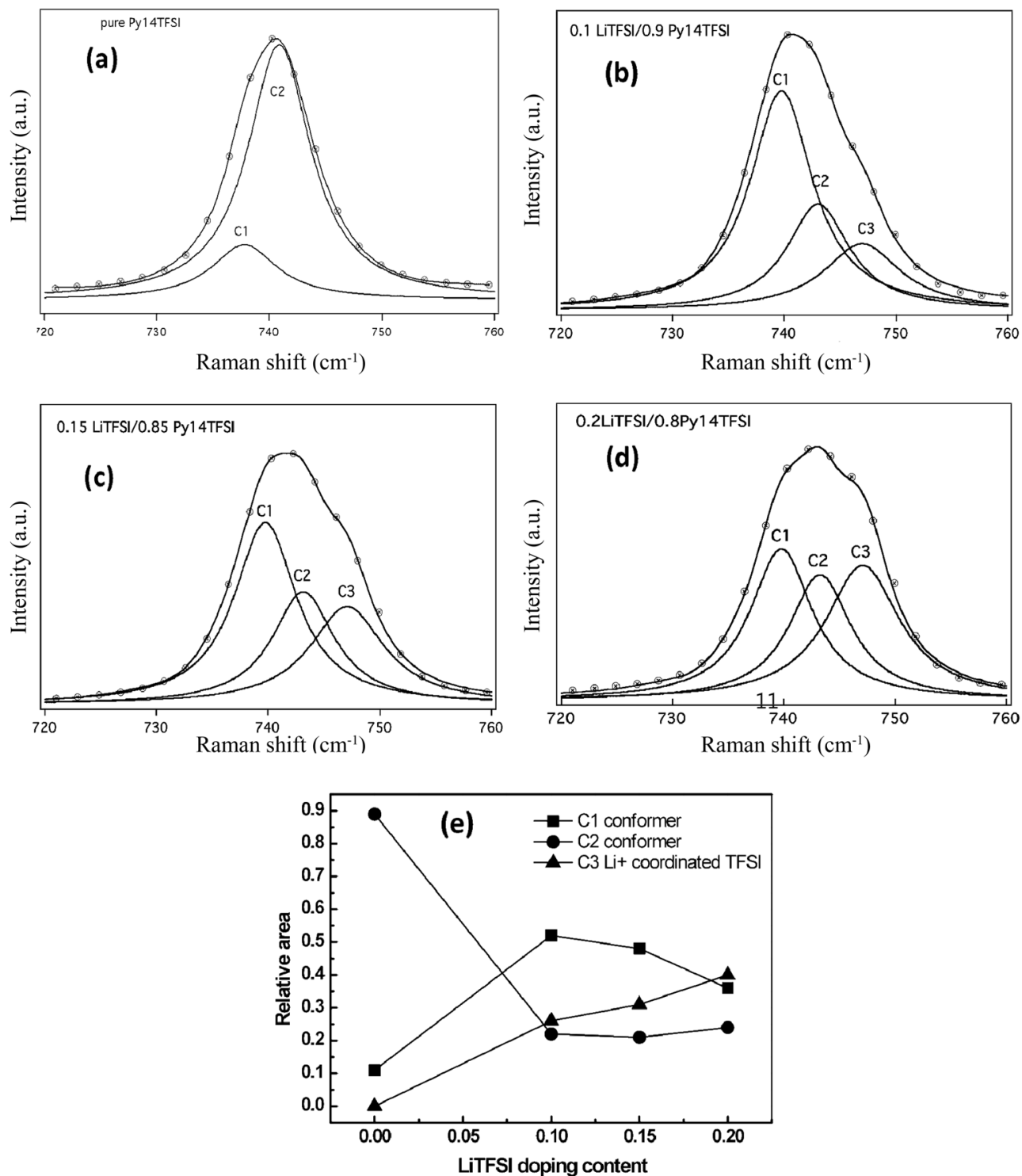

Fig. 1. Raman spectra of the $740 \mathrm{~cm}^{-1}$ mode at $25^{\circ} \mathrm{C}$ for different LiTFSI concentrations. The contributions of the two conformers $(\mathrm{C} 1, \mathrm{C} 2)$ and $\mathrm{Li}^{+}$coordinated TFSI (C3) are indicated.

Fig. 2 shows the temperature dependence of the ionic conductivity of the $\mathrm{Py}_{14}$ TFSI based electrolytes with different doping concentration of LiTFSI. It can be seen that the conductivity gradually decreases with increasing concentration of LiTFSI. This decrease can mainly be attributed to the increase in viscosity reducing the mobility of the ions. ${ }^{23,24)}$ In addition the interaction between $\mathrm{Li}^{+}$and $\mathrm{TFSI}^{-}$in stable $\left[\mathrm{Li}(\mathrm{TFSI})_{2}\right]^{-}$triplets can also reduce the number of charge carriers leading to a further decrease in the conductivity. The conductivity values at $30^{\circ} \mathrm{C}$ are presented in Table 1 . In addition, the temperature dependence of the conductivity of the electrolytes follows the Vogel-Tamman-Fulcher (VTF) behavior.

$$
\sigma=\sigma_{0} \exp \left[\frac{-B}{\left(T-T_{0}\right)}\right]
$$

In the VTF equation, $\sigma_{0}$ is the pre-exponential factor, $T_{0}$ is related to the glass transition temperature, 


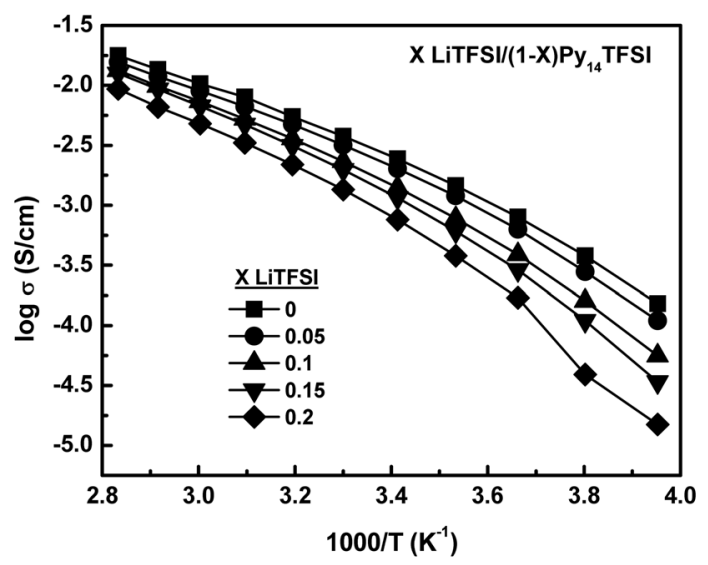

Fig. 2. Ionic conductivity as a function of temperature for Py $_{14}$ TFSI based electrolytes with different LiTFSI doping.

Table 1. Ionic conductivity at $30^{\circ} \mathrm{C}$, glass transition temperature $\left(T_{g}\right)$, and VFT parameters of ionic conductivity

\begin{tabular}{cccccc}
\hline $\begin{array}{c}\mathrm{X} \text { LiTFSI/ } \\
(1-\mathrm{x}) \mathrm{Py} \mathrm{y}_{14} \text { TFSI }\end{array}$ (S/cm) at $30^{\circ} \mathrm{C}$ & $(\mathrm{K})$ & $\left(\times 10^{2} \mathrm{~K}\right)$ & $\left(\times 10^{-1} \mathrm{~S} / \mathrm{cm}\right)$ & $(\mathrm{K})$ \\
\hline $\mathrm{X}=0$ & $3.8 \times 10^{-3}$ & 186 & 5.9 & 6.12 & 186 \\
$\mathrm{X}=0.05$ & $3.2 \times 10^{-3}$ & 189 & 5.8 & 5.4 & 189 \\
$\mathrm{X}=0.1$ & $2.3 \times 10^{-3}$ & 193 & 6.0 & 5.6 & 193 \\
$\mathrm{X}=0.15$ & $2.0 \times 10^{-3}$ & 197 & 5.9 & 5.7 & 196 \\
$\mathrm{X}=0.2$ & $1.4 \times 10^{-3}$ & 201 & 5.8 & 4.3 & 201 \\
\hline
\end{tabular}

and $\mathrm{T}$ is the absolute temperature. The VFT parameters determined form fit to the conductivity data are reported in Table 1.

Fig. 3 shows the phase behavior of $\mathrm{Py}_{14}$ TFSI as a function of LiTFSI doping concentration. Pure Py $\mathrm{y}_{14} \mathrm{TFSI}$ has a glass transition temperature $\left(\mathrm{T}_{\mathrm{g}}\right)$ at $-87^{\circ} \mathrm{C}$ and a sharp crystallization peak before two endothermic peaks. This result is in agreement with previous studies on Li-TFSI doped $\mathrm{Py}_{14}$ TFSI. $^{25,26}$ However, one should note that the exact phase behavior is dependent on the thermal history of the material due to the existence of several different crystalline forms. The first endothermic peak corresponds to the transition from a metastable phase, at $-18^{\circ} \mathrm{C}$, and the second endothermic peak to the final melting of the material at sub-ambient temperature, $-8^{\circ} \mathrm{C}$. The glass transition can be observed to shift to higher temperatures with increasing LiTFSI doping, see Table $1{ }^{25}$ ) Moreover, multiple endothermic peaks are observed at the highest concentration $(\mathrm{x}=0.2)$, pointing towards the existence of more than one crystalline phase
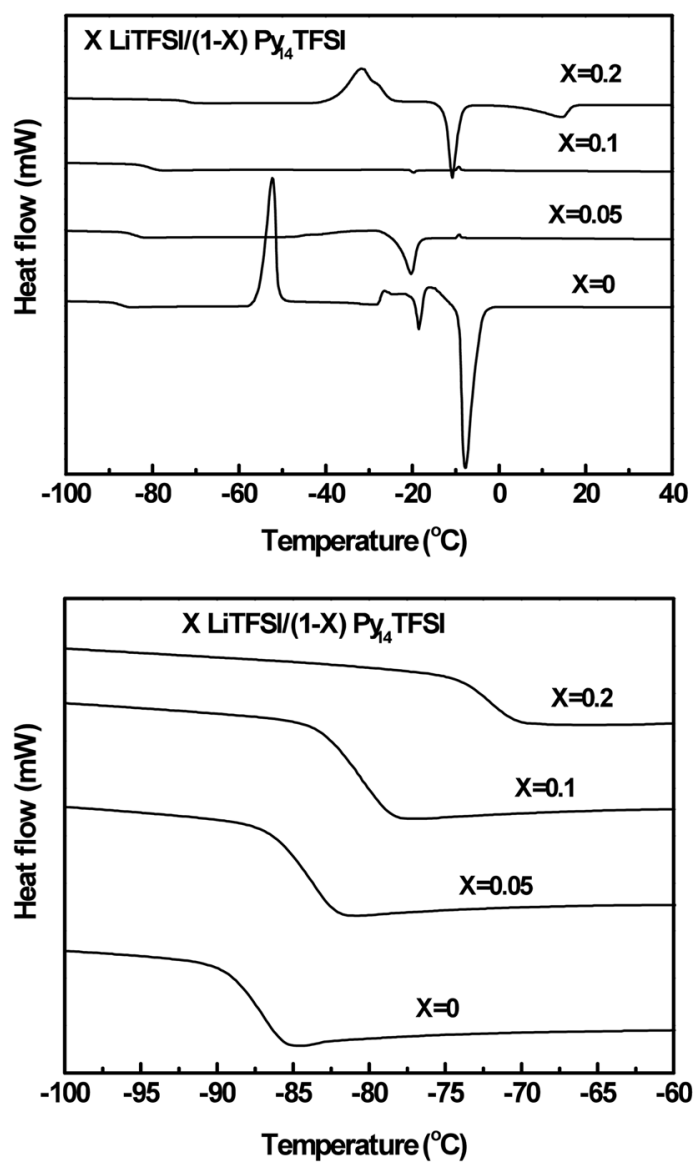

Fig. 3. DSC thermograms of Py $y_{14}$ TFSI based electrolytes with different LiTFSI doping. Magnification of the $T_{g}$ region.

also in the LiTFSI doped ionic liquid.

Fig. 4 shows the electrochemical stability limits of the $\mathrm{Py}_{14}$ TFSI based electrolytes from linear sweep voltammogram (LSV) measurements. The values are obtained from a half-cell of $\mathrm{Li} / \mathrm{Li}+$, as usual for lithium batteries. The pure $\mathrm{Py}_{14}$ TFSI displays a value of $3.5 \mathrm{~V}$ with a small peak at $4.0 \mathrm{~V}$. The addition of the LiTFSI causes a significant increase of the electrochemical stability to $5.35 \mathrm{~V}$ for $\mathrm{x}=0.2$. Moreover, the small peak at $4.0 \mathrm{~V}$ decreases with increasing LiTFSI concentration and disappears at $\mathrm{x}=0.1$. The Py ${ }_{14}$ TFSI based electrolyte with a $5.2 \mathrm{~V}$ window is thought to be acceptable for high voltage cathode materials, such as $\mathrm{LiCoO}_{2}, \mathrm{LiCoPO}_{4}$, and $\mathrm{LiMn}_{2} \mathrm{O}_{4}$. According to the LSV result, LiTFSI doping enhances the electrochemical 

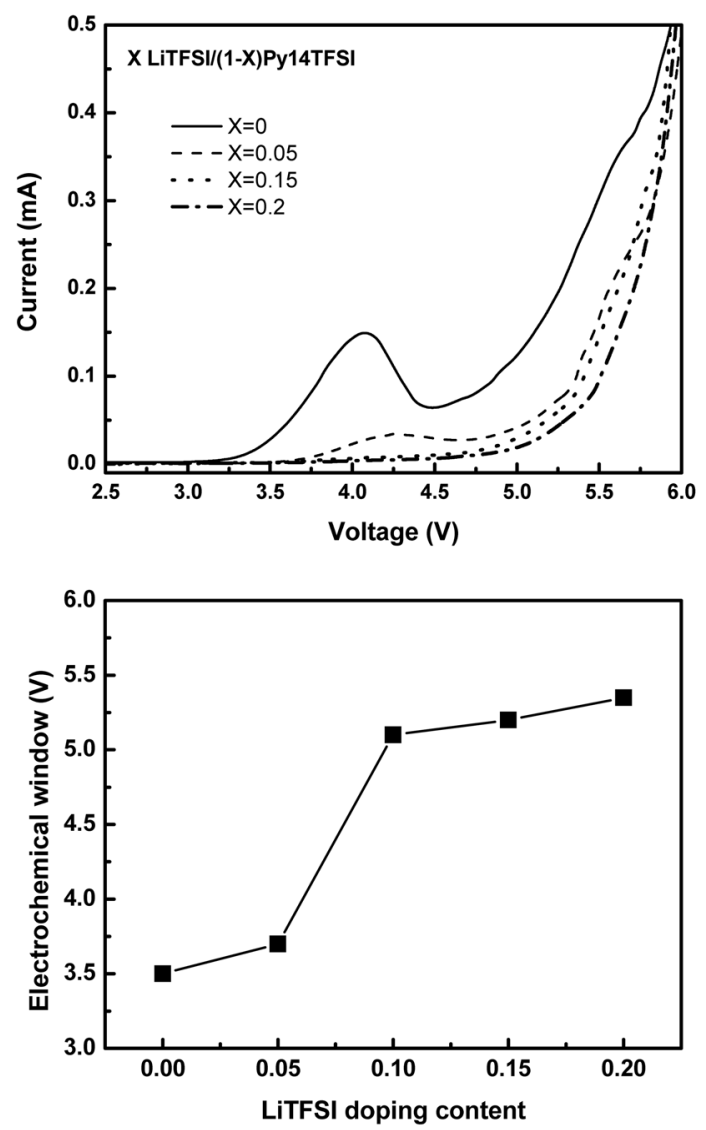

Fig. 4. Electrochemical stability limits of Py ${ }_{14}$ TFSI based electrolytes with different LiTFSI doping on oxidation process.

stability. One can speculate that the increased stability is due to that $\mathrm{Li}^{+}$coordination TFSI is more stable than free TFSI. However, to firmly explain this finding further systematic investigations are needed.

\section{Conclusions}

We find that the ionic conductivity decreases with increased LiTFSI doping accompanied by an increase glass transition temperature $\left(\mathrm{T}_{\mathrm{g}}\right)$. We also find that the electrochemical stability increases, from $3.5 \mathrm{~V}$ to $5.35 \mathrm{~V}$ with increasing the doping from $x=0$ to $x=0.2$. From Raman spectroscopy we find that the number of TFSI anions coordinated to $\mathrm{Li}^{+}$increases with LiTFSI. In the concentration range $\mathrm{x}=0.1-0.2$ the average coordination number of $\mathrm{TFSI}^{-}$around each $\mathrm{Li}^{+}$is 2 , pointing towards the existence of very stable $\left[\mathrm{Li}(\mathrm{TFSI})_{2}\right]^{-}$triplets.

\section{Acknowledgements}

The present work was supported by STINT and NRF in a joint Korea-Sweden research program, FORMAS, and the Chalmers Area of Advance-Energy.

\section{References}

1. P. Wasserscheid and W. Keim, 'Ionic Liquids-New "Solutions" for Transition Metal Catalysis' Angew. Chem. Int., 39, 3772 (2000).

2. M. Galiński, A. Lewandowski, and I. Stẹpniak, 'Ionic liquids as electrolytes' Electrochim. Acta, 51, 5567 (2006).

3. M. Armand, F. Endres, D.R. MacFarlane, H. Ohno, and B. Scrosati, 'Ionic-liquid materials for the electrochemical challenges of the future' Nat. Mater., 8, 621 (2009).

4. M. Holzapfel, C. Jost, and P. Novák, 'Stable cycling of graphite in an ionic liquid based electrolyte' Chem. Commun., 2098 (2004).

5. S. Forsyth, J. Golding, D.R. MacFarlane, and M. Forsyth, ' $N$-methyl- $N$-alkylpyrrolidinium tetrafluoroborate salts: ionic solvents and solid electrolytes' Electrochim. Acta, 46, 1753 (2001)

6. S. Ferrari, E. Quartarone, P. Mustarelli, A. Magistris, S. Protti, S. Lazzaroni, M. Fagnoni, and A. Albini, 'A binary ionic liquid system composed of N-methoxyethyl-Nmethylpyrrolidinium bis(trifluoromethanesulfonyl)-imide and lithium bis(trifluoromethanesulfonyl)imide: A new promising electrolyte for lithium batteries' J. Power Sources, 194, 45 (2009).

7. J. Huang, and A.F. Hollenkamp, 'Thermal behavior of ionic liquids containing the FSI anion and $\mathrm{Li}^{+}$cation' $J$. Phys. Chem. C, 114, 21840 (2010).

8. H. Sakaebe, and H. Matsumoto, ' $N$-Methyl- $N$-propylpiperidinium bis(trifluoromethanesulfonyl)imide (PP13-TFSI) -novel electrolyte base for Li battery' Electrochem. Commun., 5, 594 (2003).

9. A. Noda, K. Hayamizu, and M. Watanabe, 'Pulsed-gradient spinecho ${ }^{1} \mathrm{H}$ and ${ }^{19} \mathrm{~F}$ NMR ionic diffusion coefficient, viscosity, and ionic conductivity of non-chloroaluminate room-temperature ionic liquids' J. Phys. Chem. B, 105, 4603 (2001).

10. K.J. Fraser, E.I. Izgorodina, M. Forsyth, J.L. Scott, and D.R. MacFarlane, 'Liquids intermediate between "molecular" and 'ionic" liquids: Liquid Ion Pairs?' Chem. Commun., 3817 (2007).

11. K.-S. Kim, S. Choi, D. Demberelnyamba, H. Lee, J. Oh, B.-B. Lee, and S.-J. Mun, 'Ionic liquids based on $N$-alkyl- $N$ methylmorpholinium salts as potential electrolytes' Chem. Commun., 828 (2004).

12. S. Seki, Y. Umebayashi, S. Tsuzuki, K. Hayamizu, Y. Kobayashi, Y. Ohno, T. Kobayashi, Y. Mita, H. Miyashiro, N. Terada, and S.I. Ishiguro, 'Phase transition and conductive acceleration of phosphonium-cation-based roomtemperature ionic liquid' Chem. Commun., 5541 (2008). 
13. D. Gerhard, S.C. Alpaslan, H.J. Gores, M. Uerdingen, and P. Wasserscheid, 'Trialkylsulfonium dicyanamides - a new family of ionic liquids with very low viscosities' Chem. Commun., 5080 (2005).

14. E.-H. Cha, S.-A. Lim, D.-W. Kim, J.-K. Lee, and J.-H. Park, 'Physical properties of lithium co-polyelectrolyte based on imidazolium and ammonium-type ionic liquids' J. Korean Electrochemical Society, 13, 198 (2010).

15. W.A. Henderson and S. Passerini, 'Phase behavior of ionic liquid-LiX mixtures: pyrrolidinium cations and TFSIanions' Chem. Mater., 16, 2881 (2004).

16. J.-C. Lassègues, J. Grondin, C. Aupetit, and P. Johansson, 'Spectroscopic identification of the lithium ion transporting species in LiTFSI-doped ionic liquids' J. Phys. Chem. A, 113, 305 (2009).

17. J.-K. Kim, A. Matic, J.-H. Ahn, and P. Jacobsson, 'An imidazolium based ionic liquid electrolyte for lithium batteries' J. Power Sources, 195, 7639 (2010).

18. A. Lewandowski, and A. Swiderska-Mocek, 'Ionic liquids as electrolytes for Li-ion batteries-An overview of electrochemical studies' J. Power Sources, 194, 601 (2009).

19. S. Randström, G.B. Appetecchi, C. Lagergren, A. Moreno, S. Passerini, 'The influence of air and its components on the cathodic stability of N-butyl-N-methyl-pyrrolidinium bis(trifluoromethanesulfonyl)imide' Electrochim. Acta, 53, 1837 (2007).

20. I. Rey, P. Johansson, J. Lindgren, J.-C. Lassègues, J. Grondin, and L. Servant, 'Spectroscopic and theoretical study of $\left(\mathrm{CF}_{3} \mathrm{SO}_{2}\right)_{2} \mathrm{~N}^{-}$(TFS厂) and $\left(\mathrm{CF}_{3} \mathrm{SO}_{2}\right)_{2} \mathrm{NH}$ (HTFSI)' J. Phys. Chem. A, 102, 3249 (1998).

21. S. Duluard, J. Grondin, J.-L. Bruneel, I. Pianet, A. Grèlard, G. Campet, M.-H. Delville and J.-C. Lassègues, 'Lithium solvation and diffusion in the 1-butyl-3-methylimidazolium bis(trifluoromethanesulfonyl)imide ionic liquids' J. Raman Spectrosc., 39, 627 (2008).

22. T. Frömling, M. Kunze, M. Schönhoff, J. Sundermeyer, and B. Roling, 'Enhanced lithium transference numbers in ionic liquid electrolytes' J. Phys. Chem. B, 112, 12985 (2008).

23. H.F. Xiang, B. Yin, H. Wang, H.W. Lin, X.W. Ge, S. Xie, and C.H. Chen, 'Improving electrochemical properties of room temperature ionic liquid (RTIL) based electrolyte for Li-ion batteries' Electrochim. Acta, 55, 5204 (2010).

24. Z.P. Rosol, N.J. German and S.M. Gross, 'Solubility, ionc conductivity and viscosity of lithium salt in room temperature ionic liquids' Green Chem., 11, 1453 (2009).

25. A. Martinelli, A. Matic, P. Jacobsson, L. Börjesson, A. Fernicola, and B. Scrosati, 'Phase behavior and ionic conductivity in lithium bis(trifluoromethanesulfonyl)imide doped ionic liquids of the pyrrolidinium cation and bis (trifluoromethanesulfonyl)imide anion' J. Phys. Chem. B, 113, 11247 (2009).

26. Q. Zhou, W.A. Henderson, G.B. Appetecchi, and S. Passerini, 'Phase behavior and thermal properties of ternary ionic liquid-lithium salt (IL-IL-LiX) electrolytes' J. Phys. Chem. C, 114, 6201 (2010). 